\title{
Propagation of Electrical Trees under the Influence of Mechanical Stresses: A Short Review
}

\author{
M. G. Danikas \\ Department of Electrical \& \\ Computer Engineering, Democritus \\ University of Thrace, Power Systems \\ Laboratory, Xanthi, Greece \\ mdanikas@ee.duth.gr
}

\author{
D. Papadopoulos \\ Department of Electrical \& \\ Computer Engineering, Democritus \\ University of Thrace, Power Systems \\ Laboratory, Xanthi, Greece \\ dimopapa3@ee.duth.gr
}

\author{
Sayidul Morsalin \\ University of New South Wales, \\ School of Electrical Engineering and \\ Telecommunications, \\ Sydney, Australia \\ sayidul.moralin@unsw.edu.au
}

\begin{abstract}
The present paper deals with the phenomenon of electrical treeing in solid insulation, under the influence of mechanical stresses. In this short review, it is indicated that mechanical stressing can affect the propagation of electrical trees and-depending on whether it is tensile or compressive- it can facilitate (or render more difficult) the breakdown. In aged insulating materials, electrical trees can appear very quickly and can lead to breakdown.
\end{abstract}

Keywords-electrical trees; mechanical stresses; solid insulation; internal mechanical stresses; external mechanical stresses; partial discharges

\section{INTRODUCTION}

Electrical trees can come about from diverging electrical fields, as suggested in [1]. They usually have a distinct dendritic form, but -depending on the experimental conditions- can also acquire a bushy form. They develop from points of electric stress concentration. The latter can be either a sharp electrode edge, a sharp foreign conducting inclusion or a point where discharges in a weaker medium impinge on the dielectric surface [1]. Electrical trees may appear, among others, in extruded cables, since these are intimately related to partial discharges [2]. In most breakdowns the ultimate failure is preceded by treeing, the time interval between the beginning of a tree and the final failure may vary from microseconds to months [3]. Gaseous decomposition products may be formed during electrical tree formation [4]. It has been reported that a critical electric field is vital for the formation of a tree from a void [5]. The role of space charges in the formation of trees was discussed in [6], where the existence of a possible link between the concentration of space charges in the crystallineamorphous interfacial regions and the subsequent formation and propagation of tree channels was suggested.

However, apart from the purely electrical stresses, high voltage insulation has to also be confronted with mechanical stresses. As reported in [7], a repeated Maxwell stress $\left(\varepsilon E^{2} / 2\right.$, with $\varepsilon$ the relative permittivity of the material and $E$ the applied electric field) is induced around a needle point by the applied AC voltage. A compressive force is subsequently applied to the insulating material. A mechanical stress perpendicular to the electric field direction appears causing crazing when a critical value is reached. Crazing may develop to a void crack and gas discharges will expand the tree channel even further. Earlier work has also pointed out that repeated Maxwell stresses result into the time to initiate trees decreases with increasing frequency [8]. It is in the context of applied mechanical stresses that the present paper will try to give a short review of the propagation of electrical trees. In the context of the present review no mention will be made of water trees, which are altogether another significant factor affecting the lifetime of electrical insulations.

\section{ELECTRICAL TREES AND THEIR NATURE}

Electrical trees are a sign of insulation degradation. They consist of narrow hollow channels which are branched and have the general appearance of a botanical tree. Such a network of gas-filled channels emanates from already existing cavities or contaminants. Partial discharges may be responsible for such phenomena. If the degradation is complete, electrical trees go through the insulation and short-circuit it [9]. Ionization causes chemical reactions and allows for the breaking of chemical bonds of the polymers. Electrical trees ensue [10]. Electrical trees may acquire the form of either a specific dendritic type or a bushy form [11]. It was noted quite early that, in case of AC voltage rising at a constant rate, the maximum length of a tree channel is related quantitatively to the maximum charge pulses which accompany the development of the tree channel and that the total length of the tree channel is also related quantitatively to the power of discharges obtained with the distribution characteristics of current pulses [12]. It is evident that partial discharges and electrical treeing are intimately related.

An electrical tree may develop in three stages: first there is the period of initiation, then the period of development and after that the period of the widening of the already existing tree channels. In general, a certain amount of time is required in order for all three phases to fully develop. Electrical trees are caused because of the electrical and/or the electromechanical deterioration of an insulating material, which may exist in regions of high local electric field. Partial discharges affect the propagation of electrical trees, on the other hand the structure 
of an electrical tree may well define the type of partial discharges, which will further develop. The propagation of electrical trees and the partial discharge activity depend, among others, on the frequency and the level of the applied voltage, the geometry of the electrodes, the physico-chemical characteristics of the insulating material, the temperature and the humidity $[13,14]$.

As was reported earlier, tree propagation can be induced by partial discharges in the tree. In this case, the electric potential of the needle electrode is transferred to the tip of the tree channel through the conductive plasma of gas discharge. The observed tree length can be taken as a measure of the spatial distribution of the space charge [15]. Regarding the mechanism of the electrical tree, it has been reported that a negative homocharge is developed around the needle tip and the mobile negative charge carriers tend to move away as far as possible from the needle tip during the negative half-cycle. With the voltage to the positive half-cycle, the field at the needle tip becomes very high since the negative space charge produced previously may enhance the field towards the needle tip. Two will be the consequences: (1) it causes hole injection from the needle tip and, (2) it enhances the various recombination processes. The energy released from these recombination processes will eventually break the chemical bonds of the polymer. Low density channels will be created and so favorable conditions for subsequent impact ionization in these channels to form trees [16]. In many respects this theory is similar to that proposed in $[17,18]$. Figure 1 shows a typical electrical tree obtained in our high-voltage installation of Democritus University of Thrace with a sample of plexiglass and with a point-plane electrode arrangement. It can be clearly seen that besides the various electrical tree channels, the final channel of breakdown is also noticed.

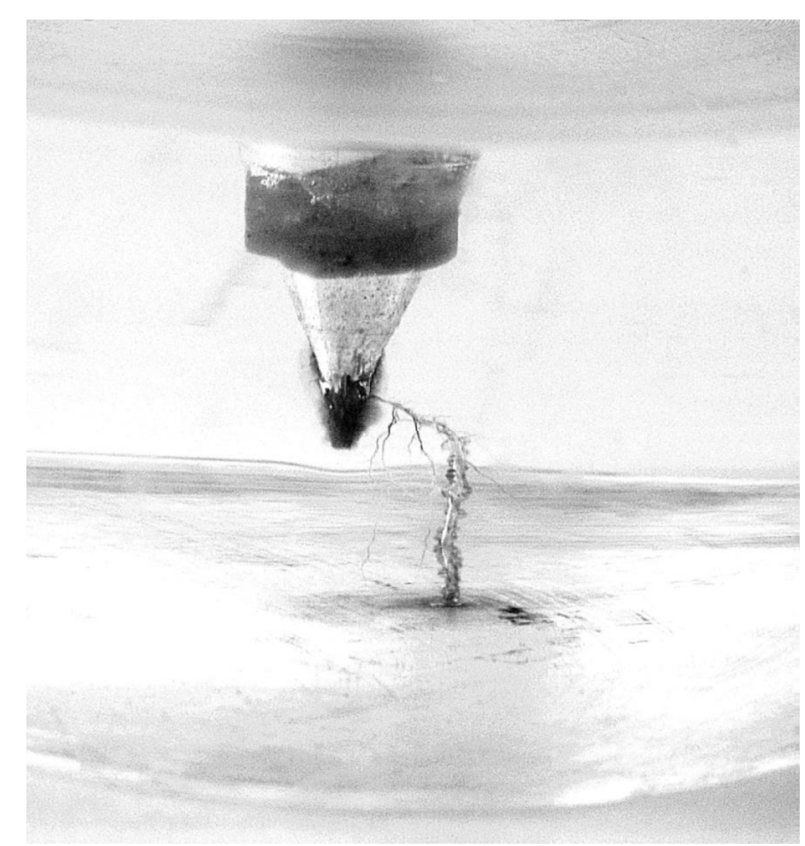

Fig. 1. Typical electrical tree channels in a plexiglass sample with a pointplane arrangement.

\section{ELECTRICAL TREES AND MECHANICAL STRESSES}

A polymer may breakdown under static stresses. When the stress in imposed for longer periods, its mechanical strength is reduced and the material suffers from brittle fracture. Brittle fracture is also accelerated from an alternating stress. The strength of the material to alternating stresses is given from a curve $\mathrm{S}-\mathrm{N}$ (where $\mathrm{S}$ is the applied stress magnitude and $\mathrm{N}$ is the number of applied cycles) [19]. Around $15 \%$ of all failures that are observed in insulating materials in service are due to crazing because of the mechanical stresses. Such stresses may originate from internal defects during the preparation of the materials or may be the result of external factors [19]. The interest of scientists and engineers about the influence of mechanical stresses on dielectric breakdown was arisen quite early [20]. It has been reported that there were indications that the decrease of dielectric strength in elevated temperatures was due to electromechanical failure. Other researchers reported that both the DC and impulse dielectric strength of polythene were increased by compression [21]. Mechanical stress appears to correlate with the percentage reduction in tree initiation voltage [21]. On the other hand, the change in the direction of tree growth observed with mechanically strained specimens indicates the formation of an electrically weak direction perpendicular to the direction of the applied tensile stress [22].

Enclosed microcavities in the insulating polymer may give a hint of a locally deformed region of the polymer. Under some high applied electric field such microcavities may be the source of partial discharges. Alternatively, some pre-existing crack or crazing in the material may accelerate a partial discharge activity. Such a repeated partial discharge activity results in electrical trees. Electrical trees may result from electron ionization of the polymer molecules, from thermal electrons, from electromechanical stresses causing the development of microcavities and from local thermal degradation. Such microcavities, cracks or crazes are far more dangerous if they are in contact with a metallic surface rather than inside the polymer [23-26]. Internal mechanical stresses may affect the behavior of electrical trees. They may influence the development of electrical trees, depending on whether the internal stresses are of tensile or of compressive nature. A reduction of the tensile strength and in fracture toughness of the polymer has as a result the reduction of its resistance to the propagation of electrical treeing [27]. High internal stresses may be introduced during the manufacturing of a cable insulation, resulting thus in either opening up existing microcavities or rendering the creation of new ones more probable. In such cases, partial discharges may be initiated and electrical trees may ensue. It is worth noting that even strains lower than the yield stress of a cable insulation will reduce the short term AC breakdown strength [28]. It should also be noted that in [28] it was reported that in case of dry conditions partial discharges can be initiated in mechanically formed microcavities, thus causing electrical trees, whereas under wet conditions, even with low applied AC voltages Maxwell stresses will pull water into crazing zones, which in turn may eventually grow to water trees (an interpretation of the water treeing as a mechanical damaging of the polymer due to the action of local stresses of electrical origin and the explanation of the propagation of water trees in terms of plastic 
deformations of the amorphous inter- and intra-spherulitic spaces is given in [29]. However, it is beyond the scope of the present paper to also tackle the subject of water trees). A good overall picture of the development of electrical trees under dry conditions, albeit not under mechanical stresses, is given in [30].

References [27, 28, 30] conform with the data presented in [31], where externally applied tensile stress has as a result the deformation of XLPE samples and the formation of more ionizable species than in undeformed samples. Consequently, mechanical deformation results in more space charges. The reason behind this is that whereas under normal circumstances cross-linking byproducts are locked in molecular chains of XLPE, with the tensile stress applied, molecular chains start to move. Such movement may release the locked byproducts. In other words, the released byproducts form part of the ionizable species. The distinction between external mechanical stresses and internal mechanical stresses is also pointed out in [32], where it was discussed that either of them can influence the time required for inception and the extent of the growth of treeing process. The higher the mechanical stresses, shorter inception time and longer growth of electrical trees within a specified time were measured. Earlier publications remarked that a plausible mechanism of failure in electrical machine insulation can be the inception of a microcrack, in which partial discharges or electrical tree mechanisms may become operative during the final stages of breakdown [33]. It has to be noted that in [33] only external mechanical stresses were taken into account. Internal mechanical stresses from manufacturing as a cause of easier creation of electrical trees and consequently of reduction of breakdown strength in cable insulation was discussed in [34]. The importance of internal mechanical stresses in locally causing electrical field intensifications and subsequently electrical degradation mechanisms in MV cables was also discussed in [34].

Another approach was adopted by some researchers, considering that tree initiation arises from the generation of small cracks (by fatigue failure due to cyclical electrostatic forces induced by the applied voltage) and tree propagation as the result of shock waves generated by microscopic explosions within the insulating material due to localized intrinsic breakdown on the crack surfaces [35-37]. In yet another publication [38], the authors considered a system of a propagating electrical tree and the regions surrounding the tree tips. Such regions were defined as 'damage process zones' and they were considered as zones of irreversible damage (caused by electromechanical, thermal and chemical processes). Such 'damage process zones' can coalesce to larger zones, i.e. to larger microcavities. The latter in turn can form a new tree channel. Such an approach is reminiscent of the approach put forward several years ago in [39], in which the authors proposed a cumulative model for breakdown. In that publication, low-energy charge carriers are able to extend the defects and increase their density so that clusters of interacting defects may form. These clusters may grow into macroscopic defects in the direction of the applied field, which in turn will form a single channel with high probability of continuous conduction between the electrodes. Supporting theoretical evidence to [38] and [39] comes also from [40], where it was remarked that a major factor for crack development is the existence of mechanical stress together with electrically induced stress. Tree growth can be hindered by compressive forces and encouraged by tensile forces. Space charges may also influence the local electric field, as already pointed out in [31]. A developing crack generates a momentarily low pressure path along the fracture path and in the field direction. Electrical discharges may ensue. An experimental validation of the above comes from a recent study on mica/epoxy machine insulation with the aid of micro computed tomography $(\mu \mathrm{CT})$, which allows for 3-D reconstruction of the test object [41]. It was clearly shown that defects may coalesce into larger ones. Moreover, it showed that mechanical stresses may help the creation of breakdown paths.

In another study, insulating materials such as crosslinked polyethylene (XLPE), polyvinyl chloride (PVC) and polyphenylene ether (PPE), were tested regarding their mechanical properties [42]. PVC and XLPE were ductile and exhibited more elongation prior to breaking, whereas PPE exhibited brittle behavior. The durability of XLPE under strain fatigue testing was the largest, followed by PVC and PPE. Reference [42] did not present any data on electrical treeing but its data on mechanical experiments are useful in indicating which materials are deemed to be suitable for high voltage applications. Detailed analysis of the residual internal stresses in cable insulation with the aid of the photoelastic method was offered in [43], where it was shown that the highest resistance to electrical trees was observed in regions of the insulation in which the material presented the best uniformity. However, [43] did not find any significant influence of the residual mechanical stresses induced by the extrusion process on the insulation properties such as breakdown strength, tree inception voltage and tree propagation time, a conclusion that is somehow difficult to reconcile with the previous statement. The importance of mechanical stresses - mainly for electrical machines- was discussed in [44], where it was pointed out that the mechanical stress can appear in the form of compression, tension, bending, vibration, and impact. Such factors may lead to fissures in the bulk of the material or at interfaces with other materials in an insulation system, which in turn may encourage electrical trees and subsequently the breakdown.

The importance of defects or of extended defects or crazes aligned on an injecting/extracting site on an electrode was stressed in [45]. Aligned free volume defects may act as nucleation sites for bigger cracks under the appropriate conditions. Electrical tree propagation rates are mainly influenced by mechanical factors, although experimental results are sometimes confusing [45]. Electrical trees propagate preferentially in a plane perpendicular to the direction of the tensile stress. Ideas expressed in [45] are reminiscent of [39] as well as of $[17,18]$, where both coalescing of microdefects and the mechanism of injection/extraction of charge carriers were mentioned. The question of mechanical stresses together with the thermal expansion coefficients of the materials was mentioned in [46]. Mechanical stress, which may be influenced by the modulus and thermal expansion coefficients of different materials, may be further increased by electromechanically induced stresses. Such events may in turn cause electrical trees and lead to the breakdown path. In [47], experimental work 
indicated that polyester resin samples suffer from electrical trees when they are mechanically stressed and that the tree growth resistance weakens. However, the authors of [47] are not very explicit about the sort of mechanical stress they applied. The significance of mechanical properties in translucent as well as in transparent types of silicone rubber is apparent in [48], bearing also in mind the different chemical curing reactions. Although [48] was mainly orientated in studying the breakdown strength, it is also evident from some experimental data that electrical trees are affected by the mechanical properties. The complexities of electrical tree growth and the factors affecting it were analyzed in [49], where the authors, in examining mechanically pre-stressed fiber reinforced Araldite 5052 epoxy resin samples, they explained the apparent retardation of the tree growth by the compressive residual stresses in the resin, which tend to increase tree branching and therefore retard tree growth. A comparison between syndiotactic polypropylene (s-PP) and XLPE indicated that both tree branching and partial discharge activity were less in the former than in the latter. This was contributed by the researchers also to the superior mechanical properties (yield stress, ultimate stress, elongation at break and elasticity modulus) of s-PP [50]. It was reported that, in case of a tree branch reaching the ground electrode, the channel surface may re-crystallize and rapidly regain the previous breakdown strength. The combined effect of discharge gas pressure and surface melting can possibly explain the development of several parallel tree branches to the ground electrode before breakdown.

Internal residual mechanical strain was studied in [51], where the way of manufacturing of transparent insulating materials - polymethyl methacrylate (PMMA), polystyrene (PS) and polycarbonate (PC) - and its influence on electrical treeing propagation with divergent electric fields was investigated. It was reported that electrical treeing stems from micro-cracks in the vicinity of the needle electrode, and in fact from its lateral side and not from the needle tip. This implies that the residual mechanical strain -formed during the manufacturing process- plays an important role. The conclusions of [51] are in qualitative agreement with those of [43]. The conclusions of [51] were confirmed with polycarbonate samples in a later publication [52], where it was pointed out that the melt flow directions and the fringe patterns may influence the direction and propagation of electrical trees. An indirect evidence of the above is offered in [53], where an investigation of the electrical trees in outer and inner layers of different voltage rating XLPE cable insulation indicated that the growth rate of electrical trees in a $66 \mathrm{kV}$ cable is much larger than that in the higher voltage rating cables. This was attributed to the size of spherulites, the extrusion process, the crystallization state, which in turn were depended on the production process, i.e. on the inner mechanical stresses that may come about. In line with the above is also [54], where it was indicated that when the limit of mechanical elastic breakdown is surpassed, electrical trees are initiated and propagate. In conjunction to [53, 54], the researchers of [55] investigated a double electrical tree structure in XLPE and they found that the residual mechanical stress, among other factors, influenced the growth of the electrical tree and caused the insulation material around the core of XLPE cable to degrade seriously. The authors of [55] attribute the initiation and propagation of electrical trees to the charge injection-extraction mechanism, first proposed in [17, 18]. In [56], authors investigating silicone rubber, a material suitable for cable joints and cable terminals, showed that under tensile stress, the electrical tree length, fractal dimension and accumulated damage become larger as the tensile rate increases, indicating thus the higher tensile rate accelerates the treeing process. With a higher compressive rate, the opposite is true, i.e. the compressive stress retards the electrical tree propagation. The authors attributed the aforementioned phenomena to the fact that under tensile stress, the attraction bond between the molecules is weakened, whereas with a compressive stress more attraction bonds are generated and the microcavities are suppressed and consequently the initiation of electrical trees is hindered. Regarding the respective influences of the tensile and the compressive stresses on the initiation and propagation of electrical trees, the conclusions of [56] do not qualitatively differ from those of earlier publications [57]. The experimental data from $[56,57]$ confirmed earlier observations reported in [58]. Electro-mechanical stresses may irreversibly deform insulation. Such a deformation becomes partly irreversible when the electrostatic energy is equal to the cohesion energy of the polymer with the result of weak attraction bonds breaking and the possible formation of radicals. At such a point, removing the electric field will not bring back the stressed molecules in their original state [59]. Mechanical stresses in machine insulation may lead to molecule fracture, new charge carriers and generation of polar species, which in turn may lead to a change of $\tan \delta$, creation of nano- and micro-cracks, partial discharges and eventual formation of electrical trees. Needless to say that such stresses combined with electrical and thermal stresses cause the rapid breakdown of machine insulation [60].

\section{PROPOSALS FOR FUTURE RESEARCH}

In this short review an effort was made to point out some of the aspects of electrical treeing and the influence of mechanical stresses upon it. Most of the work done until now was performed with conventional insulating materials. Given the great advances in the field of polymer nanocomposites [61-63], it would be interesting to see how the various mechanical stresses act upon these materials. Some studies in a relevant direction have already been done [64]. Moreover, it would be interesting to see how both conventional insulating materials and polymer nanocomposites react to mechanical stresses which are not static in nature. An even more exciting prospect can be the designing of experiments and proposal of models in which electrical, mechanical and thermal stresses act at once on insulating materials. Regarding also what was mentioned in [28] about the possibility of lower strains than the yield stress to cause the short time AC breakdown strength, it would perhaps be worthwhile to investigate this in relation to research done years ago w.r.t. the possibility of having charging effects below inception, which in turn may shorten the lifetime of an insulation [65]. In [28], as well as in [26, 65-68], it is indicated that there may be some sort of damage even below either the yield stress or the so-called inception voltage. Such ideas may have some repercussion in estimating the remaining lifetime of insulation, especially if this is subjected to both electrical and 
mechanical stresses. Needless to note that such ideas may also have some effect on some of the known lifetime models in which a threshold level of voltage is assumed. In relation to that, it would be worthwhile to investigate the electrical trees under mechanical stresses with very low frequencies. Since partial discharge activity is inexorably related to electrical treeing, it would be interesting to follow the detectability of partial discharge activity and electrical trees at low frequencies [69].

Another possibility for further work may be the simulation of electrical trees under both the influence of electrical and mechanical stressing. Until now there were numerous publications on the simulation of electrical trees in solid insulation [70-75] but not much work has been done on the simulation of trees under the influence of the above mentioned stresses. Still another possibility for further research would be the investigation of the role of mica barriers in machine insulation under the influence of both electrical and mechanical stresses. Until now a lot of work has been done regarding either the effect of mica barriers in delaying electrical trees [76] or the simulation of electrical trees within machine insulation [77]. The prospect of experimentally investigating electrical tree propagation in machine insulation under mechanical stresses seems to be equally challenging.

\section{CONCLUSIONS}

In the present paper a short review on the propagation of electrical trees in connection of the mechanical stresses was given. Mechanical stresses, either external or internal, may influence the growth of electrical trees. The technical literature tends to indicate that electrical tree development is very sensitive to mechanical stresses. The latter tend to affect in a crucial manner the inner workings of the insulating material, providing thus possible paths to breakdown. A clear distinction between tensile and compressive stresses is given in the technical literature, with the former rendering electrical tree propagation easier, whereas with the latter electrical trees propagate with more difficulty.

\section{REFERENCES}

[1] R. Cooper, "Breakdown in solids", in: Electrical Insulation, edited by A. Bradwell, Eds. Peter Peregrinus Ltd., London, UK, pp. 32-51, 1983

[2] A. W. Stannett, "Breakdown testing and measurements on installed equipment", in: Electrical Insulation, edited by A. Bradwell, Eds. Peter Peregrinus Ltd., London, UK, pp. 261-276, 1983

[3] D. W. Kitchin, O. S. Pratt, "Treeing in polyethylene as a prelude to breakdown', AIEE Transactions on Power Apparatus and Systems, Vol. PAS-77, Pt. III, pp. 180-186, 1958

[4] E. J. McMahon, J. R. Perkins, "Evaluation of polyolefin high voltage insulating compounds; Dendrite (tree) formation under highly divergent fields", IEEE Transactions on Power Apparatus and Systems, Vol. PAS83, pp. 1253-1260, 1964

[5] Y. Shibuya, "Void formation and electrical breakdown in epoxy resin", IEEE Transactions on Power Apparatus and Systems, Vol. PAS-96, No. 1, pp. 198-206, 1977

[6] O. Dorlane, "Thermally stimulated discharge of polyethylene following a.c. stressing", IEEE Transactions on Electrical Insulation, Vol. EI-17, No. 3, pp. 199-202, 1982

[7] M. Ieda, M. Nawata, "A consideration of treeing in polymers", 1972 Annual Report of Conference on Electrical Insulation and Dielectric Phenomena, National Academy of Sciences, Washington D.C., pp. 143150,1973
[8] F. Noto, N. Yoshimura, "Voltage and frequency dependence of tree growth in polyethylene", 1974 Annual Report of Conference on Electrical Insulation and Dielectric Phenomena, National Academy of Sciences, Washington D.C., pp. 207-217, 1975

[9] A. B. Johansson, A. M. B. Sandberg, "Detection of electrical treeing in XLPE exposed to AC and DC stress", Diploma Work No. 23/2010, Chalmers University of Technology, Department of Materials and Manufacturing Technology, Gothenburg, Sweden, 2010

[10] L. A. Dissado, "Understanding electrical trees in solids: from experiment to theory", IEEE Transactions on Dielectrics and Electrical Insulation, Vol. 9, No. 4, pp. 483-497, 2002

[11] M. Kahle, Elektrische Isoliertechnik, VEB Verlag Technik, Berlin, Germany, 1988

[12] I. Arima, T. Watanabe, "Current pulses caused by electrical tree development", IEEE Transactions on Electrical Insulation, Vol. 16, No. 6, pp. 543-551, 1981

[13] M. D. Noskov, M. Sack, A. S. Malinivski, A. J. Schwab, "Measurement and simulation of electrical tree growth and partial discharge activity in epoxy resin", Journal of Physics D.: Applied Physics, Vol. 34, pp. 13891398, 2001

[14] P. Tiemblo, M. Hoyos, J. M. Gomez-Elvira, J. Guzman, A. Dardano, F. Guastavino, "The development of electrical treeing in LDPE and its nanocomposites with spherical silica and fibrous and laminar silictaes", Journal of Physics D.: Applied Physics, Vol. 41, pp. 125208-125216, 2008

[15] M. Ieda, "Dielectric breakdown process of polymers", IEEE Transactions on Electrical Insulation, Vol. 15, No. 3, pp. 206-224, 1980

[16] K. C. Kao, De Min Tu, "Formation of electrical treeing in polyethylene", Annual Report of Conference on Electrical Insulation and Dielectric Phenomena, Amherst, MA, USA, October 17-21, 1982

[17] T. Tanaka, A. Greenwood, "Effects of charge injection and extraction on tree initiation in polyethylene", IEEE Transactions on Power Apparatus and Systems, Vol. PAS-97, No. 5, pp. 1749-1759, 1978

[18] T. Tanaka, A. Greenwood, Advanced Power Cable Technology, Volume I (Basic Concepts and Testing), CRC Press, Inc., USA, 1983

[19] D. C. Wright, Environmental Stress Cracking of Plastics, Rapra Technology Ltd., Shawbury, UK, 1996

[20] R. A. Fava, "Intrinsic electric strength and electromechanical breakdown in polythene", Proceedings of IEE, Vol. 112, No. 4, pp. 819-823, 1965

[21] J. J. Fendley, N. Parkman, "Effect of impregnation, compression and temperature on electric strength of polythene and polypropylene", Proceedings of IEE, Vol. 129, Pt. A, No. 2, pp. 113-118, 1982

[22] J. W. Billing, D. J. Groves, "Treeing in mechanically strained highvoltage cable polymers using conducting polymer electrodes", Proceedings of IEE, Vol. 121, No. 11, pp. 1451-1456, 1974

[23] J. H. Mason, "The deterioration and breakdown of dielectrics resulting from Internal discharges", Proceedings of IEE, Vol. 98, Pt. I, pp. 44-59, 1951

[24] J. H. Mason, "Breakdown of insulation by discharges", Proceedings of IEE, Vol. 100 (IIA), pp. 149-158, 1953

[25] J. H. Mason, "Breakdown of solid dielectrics in divergent fields", Proceedings of IEE, Vol. 102, Pt. C, pp. 254-263, 1955

[26] A. M. Bruning, M. G. Danikas, "Report on continuing work on parallel and non-parallel electric field chemical aging of polymer cavities", 4th International Conference on Conduction and breakdown in Solid Dielectrics, Sestri Levante, Italy, June 22-25, 1992

[27] B. R. Varlow, G. J. Malkin, "Electrical treeing in mechanically prestressed Insulation", IEEE Transactions on Dielectrics and Electrical Insulation, Vol. 7, No. 6, pp. 721-724, 2000

[28] E. Ildstad, S. T. Hagen, "Electrical treeing and breakdown of mechanically strained XLPE cable insulation”, 1992 IEEE International Symposium on Electrical Insulation, Baltimore, MD, USA, June 7-10, 1992

[29] Y. Poggi, J. C. Filippini, V. Raharimalaia, "Influence of the molecular weight of low density poly(ethylene) on water treeing in relation to mechanical damaging”, Polymer, Vol. 29, pp. 376-379, 1988 
[30] S. Natarajan, M. Balasubramanian, S. Mohamed Ghouse, R. Rajesh, "Morphological studies of electrical tree due to high alternating electric fields in epoxy solid dielectrics", ARPN Journal of Engineering and Applied Sciences, Vol. 13, No. 2, pp. 512-516, 2018

[31] G. Chen, M. R. Kamaruzzaman, "Impact of mechanical deformation on space charge in XLPE", 2007 International Conference on Solid Dielectrics, Winchester, UK, pp. 510-513, July 8-13, 2007

[32] R. Arora, W. Mosch, High Voltage and Electrical Insulation Engineering, John Wiley \& Sons, Inc., USA, 2011

[33] T. S. Ramu, "Degradation of h.v. generator insulation under mechanical, electrical and thermal stresses", 1990 International Symposium on Electrical Insulation, Toronto, Canada, pp. 21-24, June 3-6, 1990

[34] B. H. Chudnovsky, Transmission, Distribution, and Renewable Energy Generation Power Equipment - Aging and Life Extension techniques, CRC Press, USA, 2017

[35] R. Schurch-Brandt, Three-dimensional imaging and analysis of electrical trees, Ph. D. Thesis, University of Manchester, Faculty of Engineering and Physical Sciences, 2014

[36] D. W. Auckland, B. R. Varlow, "Electrical treeing in solid polymeric insulation", Journal of Engineering Science and Education, Vol. 4, pp. 11-16, 1995

[37] B. R. Varlow, D. W. Auckland, "Mechanical aspects of electrical treeing in solid insulation", IEEE Electrical Insulation Magazine, Vol. 12, pp. 21-26, 1996

[38] H. Z. Ding, B. R. Varlow, "Thermodynamic model for electrical tree propagation kinetics in combined electrical and mechanical stresses", IEEE Transactions on Dielectrics and Electrical Insulation, Vol. 12, pp. 81-89, 2005

[39] A. K. Jonscher, R. Lacoste, "On a cumulative model of dielectric breakdown in solids", IEEE Transactions on Electrical Insulation, Vol. 19, pp. 567-577, 1984

[40] A. Samee, Z. H. Li, C. H. Zhang, Z. P. Huang, "Fractal cluster based aging model of electrical treeing in polymeric insulation", Information Technology Journal, Vol. 8, No. 6, pp. 855-862, 2009

[41] C. Saxen, "A $\mu$-CT investigation of the electrical breakdown mechanisms in mica/epoxy machine insulation", Examensarbete, Uppsala Universitet, Division of Applied Mechanics, Department of Engineering Sciences, Uppsala, Sweden, 2017

[42] S. K. R. Bandaru Venkata Raghava, "Deformation and durability studies of insulation polymers", M. Sc. Thesis, The Graduate Faculty of the University of Akron, 2008

[43] S. Y. Lee, Y. H. Kim, I. H. Lee, N. Amyot, "Influence of internal residual mechanical stresses on local dielectric strength of EHV extruded XLPE cables", Proceedings of Electrical Insulation Conference and Electrical Manufacturing and Coil Winding Conference, Cincinnati, Ohio, USA, pp. 345-348, October 18-20, 2001

[44] Sk Manirul Haque, J. A. Ardila Rey, A. Abubakar Masúd, Y. Umar, R. Albarracin, "Electrical properties of different polymeric materials and their applications: The influence of electric field", in: Polymer Dielectrics - Properties and Applications, Ed. Boxue Du, IntechOpen, 2017

[45] L. A. Dissado, J. C. Fothergill, Electrical degradation and Breakdown in Polymers, IEE Materials and Devices Series, Vol. 9, Peter Peregrinus Ltd. London, UK, 1992

[46] M. M. Begovic, Electrical Transmission Systems and Smart Grids, Ed. M. M. Begovic, Springer, Hedelberg, Germany, 2012

[47] M. Al-Zoubi, N. Al-Naji, A. Hamdan, Detection of electrical treeing in polyester exposed to electrical and mechanical stress, BSc Thesis, Yarmouk University, Jordan, 2015

[48] C. Lothongkam, Dielectric Strength Behavior and Mechanical Properties of Transparent Insulation Materials Suitable to Optical Monitoring of Partial Discharges, PhD Thesis, Fakultaet fuer Elektrotechnik und Informatik, Universitaet Hannover, 2014

[49] H. Z. Ding, B. R. Varlow, "The effect of material age on electrical tree growth in mechanically prestressed fiber-reinforced composite insulations", 7th International Conference on Properties and Applications of Dielectric Materials, Nagoya, Japan, June 1-5, 2003
[50] H. Holto, E. Ildstad, I. Lunde, "Characteristics of electrical treeing in extruded polypropylene and cross-linked polyethylene cable insulation", 2012 International Conference on High Voltage Engineering and Application, Shanghai, China, September 17-20, 2012

[51] O. S. Gefle, S. M. Lebedev, V. A. Volokhin, Y. P. Pokholkov, "Effect of mechanical strain on the treeing phenomena", 2007 International Conference on Solid Dielectrics, Winchester, UK, July 8-13, 2007

[52] V. A. Volokhin, O. S. Gefle, S. M. Lebedev, "Effect of the melt flow direction on the treeing process in polymeric insulation", Journal of Applied Mechanics and Technical Physics, Vol. 50, No. 1, pp. 72-79, 2009

[53] A. Xie, Shengtao Li, X. Zheng, G. Chen, "The characteristics of electrical trees in the inner and outer layers of different voltage rating XLPE cable insulation", Journal of Physics D.: Applied Physics, Vol. 42, No. 12, Art. No. 125106, pp. 1-10, 2009

[54] Y. S. Cho, M. J. Shim, S. W. Kim, "Electrical tree initiation mechanism of artificial defects filled XLPE", Materials Chemistry and Physics, Vol. 56, pp. 87-90, 1998

[55] X. Zheng, G. Chen, "Propagation mechanism of electrical tree in XLPE cable insulation by investigating a double electrical tree", IEEE Transactions on Dielectrics and Electrical Insulation, Vol. 15, No. 3, pp. $800-807,2008$

[56] B. X. Du, J. G. Su, J. Lin, T. Han, "Effects of mechanical stress on treeing growth characteristics in HTV silicone rubber", IEEE Transactions on Dielectrics and Electrical Insulation, Vol. 24, No. 3, pp. $1547-1555,2017$

[57] J. V. Champion, S. J. Dodd, G. C. Stevens, "An examination of the effect of mechanical stress on electrical breakdown in synthetic resin insulators", Journal of Physics D.: Applied Physics, Vol. 27, pp. 142147, 1994

[58] D. W. Auckland, A. A. McNicol, B. R. Varlow, "Development of strain in solid dielectric due to vibrational electrostatic forces", Journal of Physics D: Applied Physics, Vol. 23, pp. 1608-1613, 1990

[59] J. P. Crine, "Influence of electro-mechanical stress on electrical properties of dielectric polymers", IEEE Transactions on Dielectrics and Electrical Insulation, Vol. 12, No. 4, pp. 791-800, 2005

[60] C. Rusu-Zagar, P. V. Notingher, C. Stancu, "Ageing and degradation of electrical machines insulation", Journal of International Scientific Publications: Materials, Methods and Technologies, Vol. 8, pp. 526-546, 2014

[61] T. Tanaka, G. C. Montanari, R. Mulhaupt, "Polymer nanocomposites as dielectrics and electrical insulation - Perspectives for processing technologies, material characterization and future applications", IEEE Transactions on Dielectrics and Electrical Insulation, Vol. 11, No. 5, pp. 763-784, 2004

[62] T. Tanaka, "Dielectric nanocomposites with insulating properties" IEEE Transactions on Dielectrics and Electrical Insulation, Vol. 12, pp. 914928, 2005

[63] M. G. Danikas, T. Tanaka, "Nanocomposites - A review of electrical treeing and breakdown", IEEE Electrical Insulation Magazine, Vol. 25, No. 4, pp. 19-25, 2009

[64] R. Sarathi, R. Sahu, M. G. Danikas, "Understanding the mechanical properties of epoxy nanocomposite insulating materials", Journal of Electrical Engineering, Vol. 60, No. 6, pp. 358-361, 2009

[65] A. M. Bruning, D. G. Kasture, F. J. Campbell, N. H. Turner, "Effect of sub-corona current on polymer insulation life", IEEE Transactions on Electrical Insulation, Vol. 26, No. 4, pp. 826-836, 1991

[66] M. G. Danikas, "Detection and recording of partial discharges below the inception voltage with a point-plane electrode arrangement in air: Experimental data and definitions", Journal of Electrical Engineering, Vol. 61, No. 3, pp. 177- 182, 2010

[67] M. G. Danikas, X. Zhao, Y. H. Cheng, "Experimental data on epoxy resin samples: Small partial discharges at inception voltage and some thoughts on the possibility of the existence of charging phenomena below inception voltage", Journal of Electrical Engineering, Vol. 62, No. 5, pp. 292-296, 2011

[68] Y. Zhang, M. G. Danikas, X. Zhao, Y. H. Cheng, "Preliminary experimental work on nanocomposite polymers: Small partial discharges 
at inception voltage, the existence of possible charging mechanisms below inception voltage and the problem of definitions", Journal of Electrical Engineering, Vol. 63, No. 2, pp. 109-114, 2012

[69] N. Jaeverberg, H. Edin, "Applied voltage frequency dependence of partial discharges in electrical trees", 21st Nordic Insulation Symposium, Goeteborg, Sweden, June 15-17, 2009

[70] L. Niemeyer, L. Pietronero, H. J. Wiesmann, "Fractal dimension of dielectric breakdown", Physical Review Letters, Vol. 52, No. 12, pp. 1033-1036, 1984

[71] J. V. Champion, S. J. Dodd, G. C. Stevens, "Analysis and modelling of electrical tree growth in synthetic resins over a wide range of stressing voltage", Journal of Physics D: Applied Physics, Vol. 27, No. 5, pp. 1020-1030, 1994

[72] M. D. Noskov, M. Sack, A. S. Malinovski, A. J. ASchwab, "Measurement and simulation of electrical tree growth and partial discharge activity in epoxy resin", Journal of Physics D: Applied Physics, Vol. 34, No. 9, pp. 1389-1398, 2001

[73] A. El-Zein, M. Talaat, M. M. El Bahy, "A numerical model of electrical tree growth in solid insulation", IEEE Transactions on Dielectrics and Electrical Insulation, Vol. 16, No. 6, pp. 1724-1734, 2009

[74] G. E. Vardakis, M. G. Danikas, "Simulation of electrical tree propagation using Cellular Automata: The case of conducting particle included in a dielectric in pouint-plane electrode arrangement", Journal of Electrostatics, Vol. 63, No. 2, pp. 129-142, 2005

[75] H. Balamurugan, S. Venkatesh, "A review on deterministic and stochastic models for electrical treeing initiation and propagation in solid insulation systems from the perspective of prediction assessment techniques", International Journal of Engineering \& Technology, Vol. 7 , No. 4, pp. 2271-2290, 2018

[76] R. Vogelsang, B. Fruth, T. Farr, K. Froehlich, "Detection of electrical tree propagation by partial discharge measurements", 15th International Conference on Electrical Machines, Belgium, August 26-28, 2002

[77] V. A. Kioussis, M. G. Danikas, R. Satathi, G. E. Vardakis, A. Bairaktari, "Electrical trees in a composite insulating system consisted of epoxy resin and mica", Engineering, Technology \& Applied Science Research, Vol. 4, No. 4, pp. 662-668, 2014 